\title{
Uniform Marginal Pricing for the Remuneration of Distribution Networks
}

\author{
P. M. De Oliveira-De Jesús, Member, IEEE, M. T. Ponce de Leão, Member, IEEE, J. M. Yusta, Member, IEEE, \\ H. M. Khodr, Member, IEEE, and A. J. Urdaneta, Senior Member, IEEE
}

\begin{abstract}
A new method for distribution access via uniform pricing for the remuneration of distribution networks is presented. The proposed approach merges in a unified framework the investments, the optimal network operation requirements, the effect of the price elasticity of demand, and the application of hourly pricing for demand side management purposes. Hourly uniform marginal prices-understood as tariffs of use of the network-are obtained from maximum social welfare condition sending efficient signals to the utility and consumers, related to the optimal operation of the grid and use of the energy at peak and valley hours. This method is used in the context of a Performance Based Ratemaking regulation to get model companies from operational optimized real networks. Capital fees are integrated in the marginal tariff of use, by means of the New Replacement Value concept, broadly used in yardstick competition. The model is stated as a mixed-integer linear optimization problem suitable to be solved through well-known linear programming tools. The methodology has been successfully tested in a 42-bus test distribution network.
\end{abstract}

Index Terms-Distribution access pricing, power system economics, tariffs of use, yardstick competition.

\section{INTRODUCTION}

$\mathbf{T}$ HE REGULATION of the electrical distribution activity based in the traditional paradigm of the Cost of Service/Rate of Return relation $(\mathrm{CoS} / \mathrm{RoR})$ engrosses or merges two distinct activities in the distribution function: distribution and retailing. The distribution utility is considered as a natural monopoly and end-user tariffs designs are usually based on the independent application of capacity and energy charges to deal with well-known revenue reconciliation problem [1].

Other types of regulation such as performance based ratemaking (PBR), have been applied in order to incentive distribution companies to be more efficient [2]. The distribution network activity remains considered as a natural monopoly and the retailing activity is open to the market. Different regulation schemes for distribution utilities as price caps, revenue caps, and yardstick competition have been developed and applied

Manuscript received April 29, 2004; revised December 17, 2004. This work was supported by the Fundação para a Ciência e a Tecnologia Portugal FCTSFRH/BD8410/2002. Paper no. TPWRS-00235-2004.

P. M. De Oliveira-De Jesús and M. T. Ponce de Leão are with Electrical and Computer Department, Faculdade de Engenharia, Universidade do Porto (FEUP), 200-465 Porto, Portugal, and the Instituto de Engenharia de Sistemas e Computadores (INESC Porto), 4200-465 Porto, Portugal (e-mail: pdeoliv@fe.up.pt; mleao@fe.up.pt).

J. M. Yusta is with Electrical Department, Universidad de Zaragoza, Zaragoza, Spain (e-mail: jmyusta@unizar.es).

H. M. Khodr and A. J. Urdaneta are with the Energy Conversion and Delivery Department, Universidad Simón Bolívar, Caracas, Venezuela (e-mail: hkhodr@usb.ve; alberto@usb.ve).

Digital Object Identifier 10.1109/TPWRS.2005.851916 in several countries, recognizing adequate investments and operation costs, promoting loss reduction and incentives to control power quality at end-users [3].

Price cap regulations take place when the regulator sets limits or caps to the electricity prices that the utility is allowed to charge. The prices are periodically updated by the $R P I-K$ formula, taking into account annual inflation and an initial price reduction representing past efficiency achievements of the utility [4]. Under revenue cap regulation, the utility incomes are fixed by a formula that is adjusted periodically considering inflation and expected productivity improvements. Subject to this cap; utility could maximize its own profit margin through minimization costs [5]. The regulator from a quality of service viewpoint must closely supervise these schemes. A lack of supervision can derive in a perverse effect of network under-investment with severe problems in power quality. In yardstick regulation, tariff structure is determined by a comparison with a model company, obtained from the optimization of the real distribution company [4].

Independently of the selected regulatory scheme, the distribution access pricing is a fundamental issue for the regulator [6]. Tariff design procedure should be sufficiently transparent to guarantee the allocation of all costs with reasonable profit for the monopolist and a nondiscriminatory access for all agents of the market. Therefore, revenue reconciliation remains as the heart of the distribution pricing problem and historically has been addressed using different approaches [1], [15] such as a fixed "added", a fixed "multiplier", "reliability sensitive adder", and "Ramsey derivation" [15], [25].

A large number of cost allocation methods applied to remunerate transmission networks are described in the literature [3]. The direct application of transmission-pricing methods to the case of large distribution networks has several limitations and does not seem reasonable due the complexity to keep a record of all assets of distribution utilities and to identify the impact of each distribution consumer, among others [6]. The roll-in-embedded methods, also referred to as postage stamp methods, are the most common and simple, using uniform average costs, but lack of proper incentives to efficiency [23].

On the other hand, marginal pricing is broadly recognized as the core approach to an efficient economic valuation. Nodal or locational marginal prices obtained from optimal power flow (OPF) studies are successfully applied in transmission networks [10] and some of them include the effect of demand elasticity [26].

At the distribution level, embedded methods as postage stamp approach are widely applied and some marginal approaches 
have been developed to make economic appraisal of distribution networks [8], [13], [16], [17]. Generally, these methods are proposed in a nodal basis in order to obtain locational short marginal prices (or STMP). Long-term marginal prices (or LTMP) are proposed to remunerate investment requirements [28]. LTMP can only be obtained as a product of an optimal expansion plan study with hard computational efforts [6], [9].

However, these embedded and marginal models do not include fundamental aspects in deregulated environments as the optimal grid operation requirements, demand response and the use of hourly pricing for demand-side management (or DSM) purposes. In addition, the application of locational or nodal prices for medium and low voltage networks should be object of discussion and the use of a uniform marginal price instead of locational prices or uniform average prices may be considered.

This paper is a modest contribution to overcome these shortcomings, merging in a unified optimization framework the allocation of fixed and variable costs of a distribution network, through the computation of uniform marginal prices, instead of locational marginal prices, taking into account the optimal network operation requirements, the effect of the price elasticity of demand, and the application of hourly pricing for demand side management purposes.

This method may be used in the context of PBR or yardstick regulation to get model companies from optimized real networks. Tariffs of use of the network send efficient signals to the regulated utility and to the consumers, related to the optimal operation of the grid and to the use of the energy at peak and valley hours. Capital expenditure costs associated with existing assets are remunerated through the application of the concept of new replacement value (NRV). Remuneration of fixed costs associated with the optimal expansion plan cost is out of scope of this work and may be integrated in this methodology by modifying the NRV of the system using an optimized expansion plan of a model company. In addition, power quality is monitored by the regulator through a penalization policy based on the unsupplied power indexes. The proposed methodology was tested in a 42-node distribution network with 14 disconnecting switches and a total energy consumption of $59.52 \mathrm{GWh} /$ year. The optimization problem is stated as a mixed linear-integer problem, and successfully solved by means of the powerful and widely used conventional linear programming optimization tools [22].

\section{Distribution Regulation}

\section{A. The Yardstick Competition Regulation}

The tariff scheme applied to the end-users under yardstick competition regulation integrates transmission and generation components plus an added value for the distribution service (AVD). Thus, the AVD price corresponds to a tariff for use of distribution network. It's obtained from a model company planned and managed with a high efficiency criterion. This model company is benchmarked with all distribution utilities associated to the specific geographical zone [4]. Two components can be identified in the AVD price aggregation.
- Firstly, a standard investment, maintenance, and operational cost is found closely related to the annual fixed charge rate (AFCR) traditionally used in roll-in-embedded allocation cost method [24]. The computation of this annual fixed cost is based in the NRV, concerned with "the cost to renew all the works, facilities and physical goods to provide distribution service in the respective concessions" [4]. Then, AFCR can be obtained from NRV considering a capital recovery factor (or CRF) [19]

$$
A F C R=N R V \cdot C R F=N R V \cdot \frac{r(1+r)^{t}}{(1+r)^{t}-1}
$$

where $t$ is the equipment lifetime and $r$ is an adequate discount rate. Fixed costs for administration and management can be also included in AFCR.

- The second component to be integrated corresponds with the real power losses. Average loss factors of a model company are used to allocate power losses.

Then, the methodology to shape a model company can be set in four phases [4].

1) Gather information of a real company.

2) Definition of a model company structure.

3) Cost allocation in three levels: distribution voltage, low voltage, and customers.

4) Computation and adjustment of AVD indexes for a given time period.

This work introduces an alternative to obtain the cost allocation at the distribution voltage level, proposing a model to determine tariffs of use of the network based in the integration of the NRV concept with the computation of marginal losses and congestion coefficients under an optimum network operation scheme.

\section{B. Distribution Network Remuneration}

In transmission marginal pricing, global network revenue [10] can be written as function of power injections and nodal prices using the following general equation:

$$
R=\sum_{h} \sum_{k} \rho_{h, k}\left(d_{h, k}-s_{h, k}\right) .
$$

In particular, the global revenue associated to a radial distribution network is given by

$$
R=\rho_{h} \sum_{h} \sum_{k} d_{h, k}-\sum_{h} \alpha_{h} s_{h}
$$

where $\alpha$ is the per unit hourly cost of power supply $s$. The uniform marginal price $\rho_{h}$ is the same for all consumption nodes $d_{k}$ and can be expressed as sum of three terms [19]

$$
\begin{aligned}
\rho_{h}=\frac{\Delta C(\text { Operation })}{\Delta d}+\frac{\Delta C(\text { Reliability })}{\Delta d} & \\
& +\frac{\Delta C(\text { Investment })}{\Delta d}
\end{aligned}
$$

The first term is associated with the marginal energy cost including power loss component. The second term is related to 
marginal shortage cost and the third term corresponds to change in the investment cost in response to load changes.

The allocation of investment costs could be made using several methodologies described in the literature [21], [23]. A traditional roll-in-embedded approach [24] is applied to pricing investment costs through an hourly investment cost per power unit $\gamma$ in $[\$ / M W h]$ using the AFCR, annual peak demand ADP, and the annual load factor LF, as follows:

$$
\gamma=\frac{\Delta C(\text { Investment })}{\Delta d}=\frac{A F C R}{A D P \cdot L F \cdot 8760} .
$$

The decomposition of an hourly marginal price $\rho_{h}$ [18] applied to an end-user can be described as the sum of marginal cost of energy $\alpha_{h}$ and the tariff of use of the distribution network $\eta_{h}$

$$
\rho_{h}=\alpha_{h}+\eta_{h} \quad \text { where } \quad \eta_{h}=\alpha_{h} \frac{\partial P_{l o s s}}{\partial d_{h}}+\mu_{h}+\gamma .
$$

The difference of nodal marginal approach with regard to the uniform scheme stays in the fact that marginal losses component and congestion $\mu_{h}$ factors do not depend of spatial distribution of load and additional charges obtained are paid throughout all consumers. We can observe that the expression (6) corresponds with the additive form to deal with revenue reconciliation approach resolution formulated in [1]. Tariff $\eta$ includes fixed costs, loss and congestion components. Thus, global network revenue $R$ can be decomposed in

where

$$
R=R_{F I X E D}+R_{L O S S}+R_{C O N G}
$$

$$
\begin{aligned}
R_{\text {FIXED }} & =\sum_{h} \sum_{k} \gamma d_{h, k} \\
R_{L O S S} & =\sum_{h} \sum_{k} \alpha_{h}\left(1+\frac{\partial P_{\text {LOSS }}}{\partial d_{h, k}}\right) d_{h, k}-\sum_{h} \alpha_{h} s_{h} \\
R_{C O N G} & =\sum_{h} \sum_{k} \mu_{h} d_{h, k}=\sum_{h} \sum_{k}\left(\rho_{h}-\gamma\right) d_{h, k}-\alpha_{h} s_{h} .
\end{aligned}
$$

As power losses are linearized, there is revenue reconciliation of losses, then $R_{L O S S}$ is always equal to zero.

\section{The Consumer as a Market Agent}

Electricity markets are submerged in a deeply deregulation process and consumers will be exposed to volatile electricity real-time prices and may decide to adjust the profile of their demand to reduce electricity costs [11]. This demand-price relationship may be illustrated by a curve drawn in Fig. 1 .

This curve is difficult to quantify and often is linearized around a given point $\left(\rho_{0}, d_{0}\right)$. Then, the price elasticity of demand at time $t$ is defined as the relative slope of this curve as follows [29]:

$$
\varepsilon_{h}=\frac{\frac{\Delta d_{h}}{d_{o}}}{\frac{\Delta \rho_{h}}{\rho_{o}}}
$$

From this point on, it will be assumed that all prices and demands have been normalized with respect to a known equilibrium point [12]. The elasticity parameter is described as

$$
\varepsilon_{h}=\frac{\Delta d_{h}}{\Delta \rho_{h}}
$$

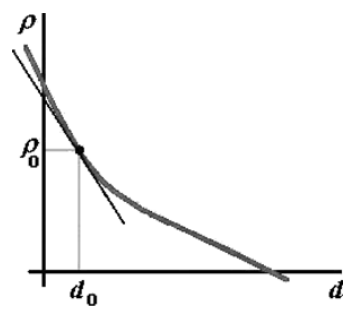

Fig. 1. Demand curve.

the linear price and demand function can then be written, respectively, as

$$
d_{h}=d^{\max }-\varepsilon_{h} \rho_{h}
$$

and

$$
\rho_{h}=\rho^{\max }-\beta_{h} d_{h} ; \quad \beta_{h}=\varepsilon_{h}^{-1} .
$$

The value of $d_{h}$ depends directly on the elasticity value at hour $h$ and the maximum price paid by the consumer $\rho^{\max }$, and the value of $\rho_{h}$ depends on the inverse of the elasticity value at hour $h$ and the maximum consumption capacity of consumer $d^{\max }$. Finally, the customer benefit function obtained by using of $d_{h}$ is required to evaluate the Social Welfare and it can be found by means of the classic definition [29]

$$
B_{h}(d)=\int \rho_{h} \partial d_{h}
$$

\section{PROPOSED MEthodology}

The methodology presented in this paper is supported by the theory of social welfare and natural monopoly regulation [1], [29]. The proposed model utilizes the spot price scheme for distribution systems presented in [7], introducing an uniform marginal price instead of a set of local marginal prices.

The general OPF problem is stated in (13)-(17), where the total Social Welfare $S W$ is maximized subject to the equations that describe the demand response, the network energy balance equations, the maximum limits on the power flows due to equipment capacities, and to the equations that ensure the radial operation condition.

$\max S W=\max$ Consumer Benefit $(d)-$ Supply Cost $(s)$

-Fixed Investment Cost $(d)-$ Reliability Cost $(d)$

subject to

$$
\begin{aligned}
& \text { Demand Response }(\rho) \\
& \text { Network Energy Balance Equations }(d, X) \\
& \text { Power Flow Limits }(d) \\
& \text { Radial Operation Condition }(X) \text {. }
\end{aligned}
$$

The marginal price $\rho$ is obtained for the maximum social welfare condition and optimal grid operation topology by way of the introduction of decision integer binary variables $X$. A disconnecting switch is associated to each power line through a binary variable, which is set to 1 if the device is closed or not installed, and 0 if it is open. 
The supply cost is a compound of generation as well as transmission costs (i.e. generation capacity charges and transmission complementary charges) plus energy costs.

Energy costs can be obtained either through pool mechanisms - wholesale energy market - or by knowledge of bilateral contracts between the producers and distribution utility. Fixed investment costs are obtained from an economic assessment of the physical network following the NRV philosophy. Reliability cost is evaluated using the unsupplied power index.

The proposed methodology allows the regulator to determine uniform marginal prices discriminated by the hour of the day, week, month, etc. The prices are obtained by solving the optimization problem presented in (18)-(22) using a specified temporary base $T$, given in hours. For example, a day study requires a 24-hour or 48 half-hour time base, according to the spot market or to bilateral contract arrangements. Symbol and acronym definitions can be found in detail in the Appendix

$$
\begin{aligned}
\max \sum_{h} \sum_{k} B_{h, k}-\sum_{h} \alpha_{h} s_{h}-\gamma \sum_{h} \sum_{k} d_{h, k} \\
-G \sum_{h} \sum_{k} P N S_{h, k}
\end{aligned}
$$

subject to

$$
\begin{aligned}
& d_{h, k}=d_{k}^{\text {max }}-\varepsilon_{h, k} \rho_{h} \quad k=1, \ldots, n ; h=1, \ldots, T \\
& l_{h, j} \leq l_{j}^{\text {max }} \quad j=1, \ldots, m ; h=1, \ldots, T \\
& \sum_{\substack{\text { Lines } I N \\
\text { node } k}} l_{h, j}\left(1-p_{j}\right) \cdot X_{h, j}-\sum_{\substack{\text { Lines oUT } \\
\text { node } k}} l_{h, j} \cdot X_{h, j}=d_{h, k} \\
& j=1, \ldots, m ; k=1 \ldots . n, h=1, \ldots, T \\
& \sum_{\substack{\text { Lines IN } \\
\text { node } k}} X_{h, j}=1 \\
& j=1, \ldots, m ; k=1 \ldots n, h=1, \ldots, T .
\end{aligned}
$$

Capital expenditure is set through the hourly investment cost per power unit $\gamma$. Unsupplied power is evaluated taking into account the cost of the undelivered power and statistical data regarding frequency of outages $\lambda_{k}$ and the mean time between failures value $M T B F_{k}$ in each consumption node [20]

$$
P N S_{h, k}=\lambda_{k} \cdot M T B F_{k} \cdot d_{h, k} .
$$

The social welfare function has a nonlinear behavior due to a quadratic consumer benefit function. To solve the optimization problem, the consumer benefit function is linearized by its decomposition into two or more linear sections according the degree of nonlinearity. This procedure has been successfully applied for objective function linearization for optimum power flow studies [30]. Also, the power loss components in the network energy balance equations are linearized as described in the large-scale distribution planning model proposed in [14], [27].

The introduction of binary variables related to the disconnecting switches assures the topology of an efficiently operated radial distribution network. The optimal power flow problem stated in (18)-(22) constitutes a mixed linear-integer problem suitable of resolution using conventional linear programming algorithms specially suited to large-scale problems [22].
Different price strategies can be introduced in the model, such as the computation of a flat price for the entire specified time interval $T$ :

$$
\rho_{h}=\rho^{\text {flat }} \quad h=1, \ldots, T
$$

or the determination of $b$ flat prices in $b$ time block intervals

$$
\rho_{h}=\rho^{i} \quad h \in T_{i} \quad i=1, \ldots, b .
$$

The prices are applied uniformly for all consumers of the distribution network but are also discriminated by the different time block intervals.

These features allow the regulator to set prices at a certain time interval introducing the consideration of demand side management strategies, promoting off-peak consumption at low prices and penalizing peak hour consumption through high prices. DSM strategy consists of the application of a fixed price $\rho^{\text {fixed }}$ during the specified DSM time interval, including an additional constraint

$$
\rho_{h}=\rho^{\text {fixed }} \quad h \in D S M \text { Interval. }
$$

Prices out of the DSM interval are computed using the proposed model that permits the calculation of the optimal uniform marginal prices for a maximum social welfare condition and optimal grid operation. This strategy does not affect the total remuneration of the distribution network. Adequate profit of the monopolist remains guaranteed in the discount rate decided in the definition of AFCR and the hourly investment cost per power unit $\gamma$. Optimum solution may derive in different network topologies for each time interval.

\section{RESULTS}

The proposed methodology was applied to a 42-node distribution network with a total consumption of $59.52 \mathrm{GWh} /$ year. The radially operated system includes 14 disconnecting switches that allow configuration changes during normal operation. Distribution utility buys energy at the spot market without considering the capacity charges for remuneration of generation and transmission systems. Line data, consumer response characteristics, and wholesale market spot prices can be found in the Appendix.

Hourly marginal prices $\rho_{h}$ were obtained for a typical 24-hour day, considering three scenarios, as follows.

1- Computation of hour-by-hour (hourly prices), three-block (8-h prices) and flat prices (24-h prices) neglecting line flows congestion.

2- Computation of hourly prices considering line flows congestion.

3- Computation of hourly prices considering DSM strategy to reduce peak consumption.

Tariffs of use of the network $\eta$ were calculated and discussed for each scenario. Annual Fixed Charge Rate was set in 2.714 million $\$ y r$ considering a NRV of $\$ 27.5$ million, a discount rate of $9.45 \%$, and an equipment lifetime of 35 years. In consequence, the hourly investment cost per power unit $\gamma$ is equal to $4.55 \mathrm{c} \$ / \mathrm{kWh}$. Hourly elasticity parameters were determined for each load demand value using the maximum load points 


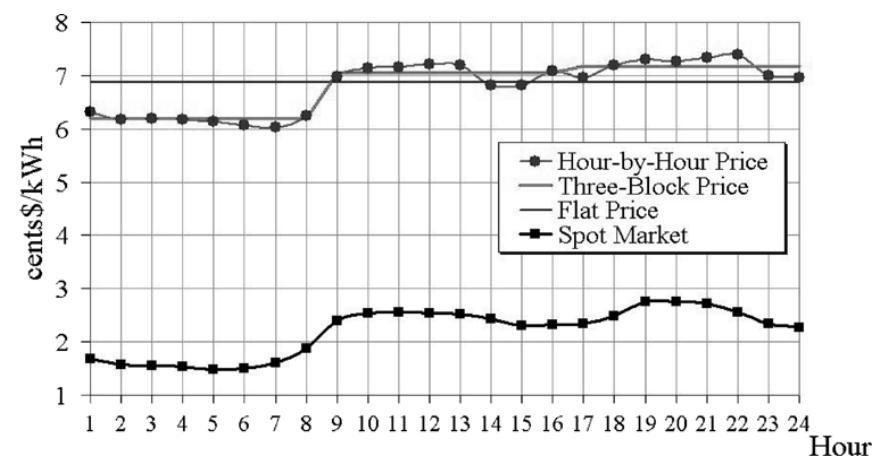

Fig. 2. Hourly marginal prices (neglecting congestion).

given in Table VI and the daily load curve shown in Fig. 5 of the Appendix. Equilibrium price $\rho_{0}$ is set in $5.8 \mathrm{c} \$ / \mathrm{kWh}$ and $\rho^{\max }$ equal to $20 \mathrm{c} \$ / \mathrm{kWh}$. This demand representation is realistic, taken into account a relatively weak response in the power consumption with respect to high changes in the prices. For a typical 24-h day problem, the optimization problem encloses 1008 real variables (984 power line flows and 24 uniform prices) and 336 binary variables.

\section{A. Scenario 1: Neglecting Power Line Congestion}

The uniform marginal prices $\rho$ applied to end-users were computed applying the model proposed using a base time of 24 $\mathrm{h}$ per day. Spot market prices were taken for a winter typical day and annual network revenue was computed extrapolating the results in 365 days. In this scenario no power flow congestion in the electric lines were considered. Block prices were specified in three flat interval prices, between hours 0-8, 9-17 and $18-24$, respectively.

As shown in Fig. 2, computed hourly price behavior is similar to the price-market trend. Results reflect the influence of the fixed cost and power losses allocation. Block price results (6.19 $\mathrm{c} \$ / \mathrm{kWh}, 7.05 \mathrm{c} \$ / \mathrm{kWh}, 7.17 \mathrm{c} \$ / \mathrm{kWh}$ ) correspond with a good fit of an hour-by-hour result. This feature is relevant, since it is simpler to communicate three prices to the consumers than 24 different hourly prices. The maximum social welfare is reached using the hour-by-hour price strategy followed closely by the three-block and the flat price strategy correspondingly. It is relevant to refer that without the congestion condition the flat price obtained ( $6.83 \$ / \mathrm{MWh})$ overlaps with the mean of the 24 hourly prices previously obtained using (27)

$$
\rho^{\text {flat }}=\frac{1}{24} \sum_{h=1}^{24} \rho_{h} \quad h=1, \ldots, 24 .
$$

The core of the proposed methodology is the computation of a tariff of use of the network $(\eta)$ required for AVD aggregation under yardstick competition regulation. It can be obtained from the end-user marginal prices $\rho$, obtained in the optimization process using the decomposition formula given in (6).

Fig. 3 shows the resultant energy tariffs corresponding to the end-user application of an hourly and a flat price respectively. The application of a flat marginal price $\rho^{\text {flat }}$ produces a very irregular value of $\eta$ due to generation market influence. On other hand, the application of hour-by-hour marginal price yields to a less irregular tariff that takes values around the hourly fixed

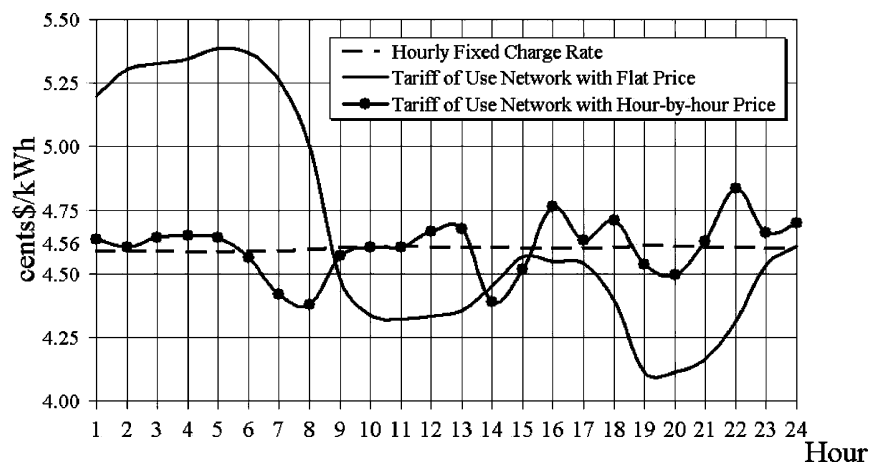

Fig. 3. Hourly tariff of use of the network.

TABLE I

ANNUAL NETWORK REMUNERATION

\begin{tabular}{l|c|c|c}
\hline \multicolumn{4}{|c}{ REMUNERATION IN \$/YEAR } \\
\hline Price Strategy & $R_{\text {FIXED }}$ & $R_{\text {CONG }}$ & $R$ \\
\hline Hour-by-hour & 2.714 .350 & 0 & 2.714 .350 \\
\hline Three-Block & 2.714 .510 & 0 & 2.714 .510 \\
\hline \multicolumn{1}{c}{ Flat } & 2.714 .530 & 0 & 2.714 .530 \\
\hline
\end{tabular}

charge rate value $\gamma$. Hence, a flat tariff of use of network $\eta^{\text {flat }}$ corresponds directly to the hourly investment cost

$$
\eta^{\text {flat }}=\gamma
$$

The utilization of a unique value of $\eta$ for all nodes allows a uniform allocation of capital costs and power losses among the consumers. This feature corresponds with several ongoing regulation processes in many countries. Although the simplicity of application is an unquestionable advantage, a traditional uniform tariff scheme does not send efficient economical signals about the physical use of the network by each consumer. This drawback is mitigated in the proposed methodology through the computation of marginal coefficients under the traditional roll-in-embedded capital cost allocation scheme.

Annual network remuneration is computed for all strategies prices in base of 365 typical days using the following expression (29) derived from (3)

$$
R=365 \sum_{h=1}^{24}\left[\rho_{h} \sum_{k=1}^{42} d_{h, k}-\alpha_{h} s_{h}\right] .
$$

Annual remuneration decomposition is obtained using (7) and is shown in Table I. Results indicate that price strategy is closely to $59.53 \mathrm{GWh} / \mathrm{yr}$ and therefore, the obtained revenue is in the order of 2.72 million $\$ / y r$ matching with the expected AFCR previously defined and assuring the revenue re-conciliation and variable costs. As expected, there are no lines that reach operational limits and the congestion revenue $R_{C O N G}$ is equal to zero. Power losses are entirely allocated to consumers and distribution revenue due to loss component $R_{L O S S}$ is equal to zero.

\section{B. Scenario 2: Congestion in Main Feeders}

Congestion in power lines requires the introduction of adjustments in the tariff structure aimed to obtain additional revenues 


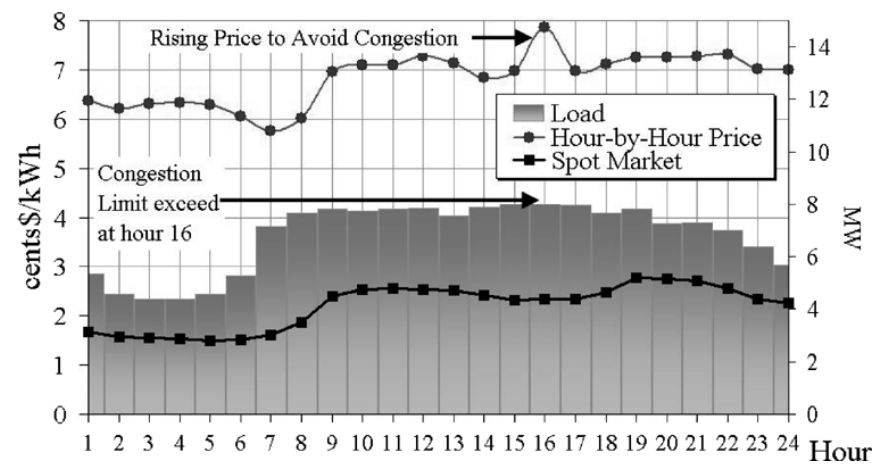

Fig. 4. Hourly marginal prices (considering congestion).

TABLE II

ANNUAL NETWORK REMUNERATION [CONGESTION]

\begin{tabular}{c|c|c|c}
\hline \multicolumn{4}{c}{ REMUNERATION IN \$/YEAR } \\
\hline Price Strategy & $R_{F I X E D}$ & $R_{C O N G}$ & $R$ \\
\hline Hour-by-hour & 2.714 .350 & 0 & 2.714 .350 \\
\hline Hour-by-hour with Congestion & 2.714 .350 & 11.070 & 2.725 .420 \\
\hline
\end{tabular}

enough to get financial adequacy of the system and to solve congestion problems. To simulate a congestion condition, power flow limit $l^{\text {max }}$ corresponding with lines $0-14,0-25$ and $0-1$ was reduced to 2, 3, and $3 \mathrm{MW}$, respectively. Fig. 4 shows the congested operation condition at hour 16 and the corresponding rising price in the hour-by-hour strategy.

Table II indicates the annual network revenue increase to 2.725 million $\$ / y r$. As scenario 1, power losses are entirely allocated to consumers and distribution revenue due to loss component $R_{L O S S}$ is equal to zero.

Congestion effect is obtained through (7) and produces an additional payment of $11.070 \$ / y r$ by the end users corresponding to $0.4 \%$ with respect to scenario 1 . This amount must be used to reinforce the distribution network and regulator supervision becomes fundamental to guarantee appropriate power supply. As scenario 2, the marginal prices applied to end-user produces an irregular hourly value of $\eta$. A flat tariff of use of network $\eta^{\text {flat }}$ can be computed taking into account the congestion component using the following relationship:

$$
\eta^{\text {flat }}=\gamma+\frac{1}{24} \sum_{h=1}^{24}\left[\rho_{h}-\alpha_{h}\right] .
$$

This value is equal to $4.63 \mathrm{c} \$ / \mathrm{kWh}$ and enough to receive the additional payment due congestion condition. An optimized distribution network utilized for benchmarking proposes must not have congestion problems. These additional congestion payments may be used as a reference to incentive grid reinforcements. It is relevant to say, that due to the elastic response of demand, the resultant prices derive in load reductions avoiding line outage. These reductions were enough to alleviate congestion conditions without network reconfiguration.

\section{Scenario 3: DSM Strategy}

An efficient DSM contributes to mitigate congestion problems and to postpone investments in network reinforcement. In

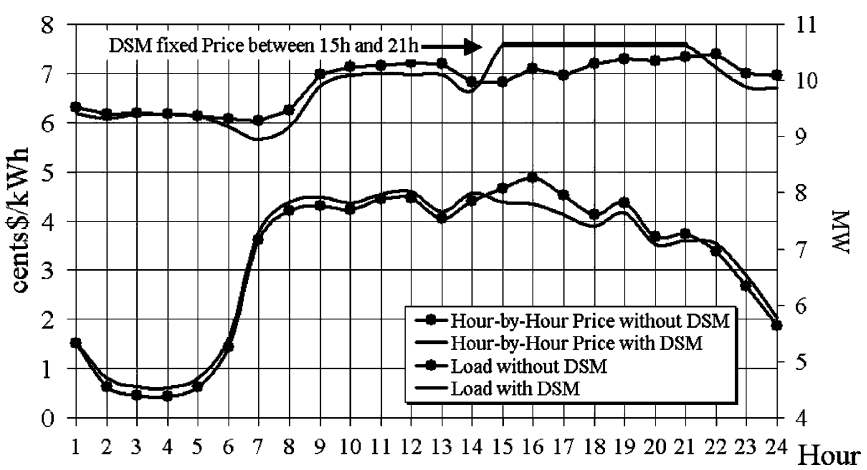

Fig. 5. Hourly marginal prices (considering DSM strategy).

TABLE III

ANNUAL NETWORK REMUNERATION

\begin{tabular}{c|c|c|c}
\hline \multicolumn{4}{c}{ REMUNERATION IN \$/YEAR } \\
\hline Price Strategy & $R_{F I X E D}$ & $R_{C O N G}$ & $R$ \\
\hline Hour-by-hour with Congestion. & 2.714 .350 & 11.070 & 2.725 .420 \\
\hline Hour-by-hour with DSM & 2.714 .650 & 0 & 2.714 .650 \\
\hline
\end{tabular}

TABLE IV

OPTIMUM NETWORK TOPOLOGY

\begin{tabular}{c|c||c|c}
\hline \multicolumn{4}{c|}{ DisCONNECTING SWITCH CONDITION } \\
\hline Line & Position & Line & Position \\
\hline $0-10$ & CLOSED & $10-40$ & OPEN \\
\hline $3-4$ & CLOSED & $35-39$ & CLOSED \\
\hline $7-15$ & OPEN & $10-29$ & OPEN \\
\hline $25-26$ & CLOSED & $30-31$ & CLOSED \\
\hline $18-19$ & CLOSED & $33-35$ & CLOSED \\
\hline $12-22$ & OPEN & $34-38$ & OPEN \\
\hline $24-42$ & OPEN & $35-36$ & CLOSED \\
\hline
\end{tabular}

this work we present a DSM strategy based on the application of a high price during the peak time interval expecting an elastic response of demand. The hourly prices are computed maximizing social welfare. This condition is achieved for the optimum network topology configuration. Fig. 5 shows the results of the application of DSM strategy setting a fix price of $7.56 \mathrm{c} \$ / \mathrm{kWh}$ during the peak time interval: $15 \mathrm{~h}-21 \mathrm{~h}$. The resultant load curve is adjusted at the peak interval time avoiding congestion problems at main substation feeders (same as scenario 2).

Conversely, hourly marginal prices drop at off-peak interval time, encouraging power consumption at off-peak hours.

Table III shows that the annual network revenue decreases slightly with respect to the hour-by-hour price strategy (obtained in scenario 2). Due to DSM strategy, there is no congestion and no additional congestion payments. DSM strategies produce a peak load reduction of 5\% at hour 16 and encourage risen consumptions at valley hours.

Finally, as indicated in Table IV, the same solution is obtained for the optimum network topology in the three explored scenarios. Due to the elasticity of demand the load profile is adjusted in order to avoid line congestion without network reconfiguration. These results should not be considered as a general rule. More general and severe congestion conditions may derive in a different topology schemes in order to avoid line congestion conditions at peak hours. 


\section{CONCLUSION}

A new method of distribution access pricing is discussed, merging in a unified optimization framework the allocation of fixed and variable costs of a distribution network, through the computation of uniform marginal prices, taking into account the optimal network operation requirements, the effect of the price elasticity of demand, and the application of hourly pricing for demand-side management purposes. Uniform marginal pricing method sends efficient price signals to the utility related to the optimal operation of the grid. Price signals are given to the consumers by the use of the energy at peak and valley hours. The method derives in a well-known optimization model suitable to be solved in large-scale test cases by means of standard programming tools.

\section{APPENDIX LIST OF SYMBOLS}

$\alpha$

$\beta$

b

$B$

$d$

$d^{\max }$

$\varepsilon$

G

$\lambda$

$l$

$l^{\max }$

$\eta$

$n$

$m$

$\mu$

$p$

$\rho$

$\rho^{\max }$

$\rho^{\text {fixed }}$
$\rho^{\text {flat }}$

$r \quad$ Annual discount rate [\%].

$R \quad$ Global Network Revenue [\$/yr].

$R_{F I X E D}$ Network Revenue by fixed costs [\$/yr].

$R_{L O S S} \quad$ Network Revenue by power losses [\$/yr].

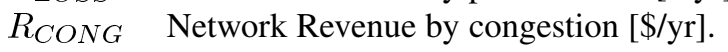

$s \quad$ Power supply [MW].

$t \quad$ Equipment lifetime [yr].

$T \quad$ Number of hours, temporary base.

$\gamma \quad$ Hourly investment per power unit [\$/MWh].

$X \quad$ Decision variable associated to disconnecting switch position.

\section{SUB-INDEXES}

$i$
$h$
$j$
$k$

associated to time interval $i$.

associated to hour $h$.

$\begin{array}{ll}j & \text { associated to line } j . \\ k & \text { associated to node } k \text {. }\end{array}$

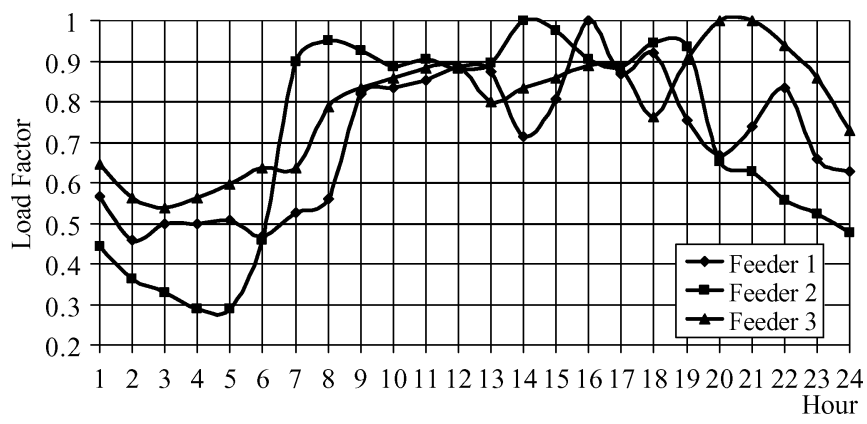

Fig. 6. Daily load curve.

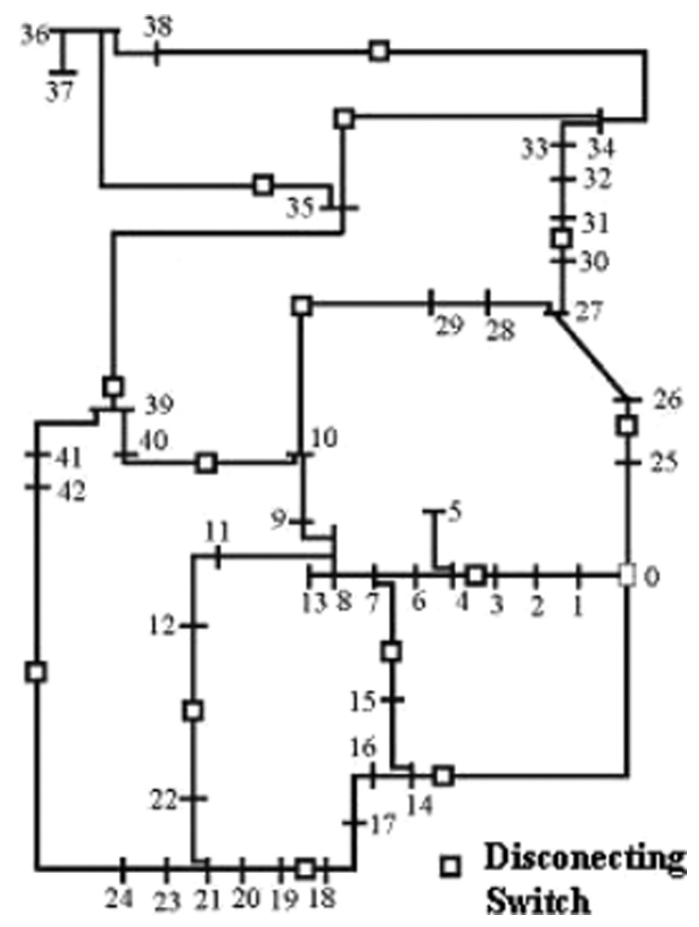

Fig. 7. 42-node distribution test system.

\section{ACRONYMS}

AFCR Annual Fixed Charge Rate [\$/yr].

$A D P \quad$ Annual Demand Peak [MW].

$A V D \quad$ Added Value of Distribution [\$/MWh].

$C R F \quad$ Capital Recovery Factor.

$D S M \quad$ Demand-Side-Management.

$H F C R \quad$ Hourly Fixed Charge Rate [\$/yr].

$M T B F \quad$ Mean time between failures [hr/yr].

$N R V \quad$ New Replacement Value [\$/yr].

$L F \quad$ Annual Load Factor.

LTMP Long Term Marginal Price [\$/MWh].

$O P F \quad$ Optimal Power Flow.

PBR Performance Based Ratemaking.

$P N S \quad$ Power not supplied [MW].

$R P I \quad$ Retail Price Index plus an Efficiency Factor K.

STMP Short Term Marginal Price [\$/MWh].

$S W \quad$ Social Welfare $[\$ / y r]$.

\section{The 42-Node Distribution Test System}

Test system corresponds to a 42-node, three feeder distribution network operated at 12.47-voltage level. Fig. 6 specifies the daily load curve in each feeder. Fig. 7 shows the network 
TABLE V

MAXIMUM LOAD AND FEEDER LOCALIZATION

\begin{tabular}{c|c|c||c|c|c||c|c|c}
\hline Node & $\begin{array}{c}d^{\text {max }} \\
{[k W]}\end{array}$ & Feeder & Node & $\begin{array}{c}d^{\text {max }} \\
{[k W]}\end{array}$ & Feeder & Node & $\begin{array}{c}d^{\text {max }} \\
{[k W]}\end{array}$ & Feeder \\
\hline 1 & 152.1 & 1 & 15 & 28.4 & 2 & 29 & 276.1 & 3 \\
\hline 2 & 318.1 & 1 & 16 & 364.9 & 2 & 30 & 191.7 & 3 \\
\hline 3 & 145.6 & 1 & 17 & 356.3 & 2 & 31 & 191.7 & 3 \\
\hline 4 & 292.8 & 1 & 18 & 514.7 & 2 & 32 & 184.1 & 3 \\
\hline 5 & 76.0 & 1 & 19 & 178.8 & 2 & 33 & 184.1 & 3 \\
\hline 6 & 216.2 & 1 & 20 & 91.2 & 2 & 34 & 222.4 & 3 \\
\hline 7 & 142.4 & 1 & 21 & 213.3 & 2 & 35 & 276.1 & 3 \\
\hline 8 & 84.1 & 1 & 22 & 537.5 & 2 & 36 & 118.9 & 3 \\
\hline 9 & 94.9 & 1 & 23 & 152.9 & 2 & 37 & 260.7 & 3 \\
\hline 10 & 84.1 & 1 & 24 & 98.6 & 2 & 38 & 125.8 & 3 \\
\hline 11 & 57.2 & 1 & 25 & 113.5 & 3 & 39 & 131.9 & 3 \\
\hline 12 & 135.9 & 1 & 26 & 751.6 & 3 & 40 & 173.3 & 3 \\
\hline 13 & 112.7 & 1 & 27 & 431.0 & 3 & 41 & 204.0 & 3 \\
\hline 14 & 415.0 & 2 & 28 & 222.4 & 3 & 42 & 55.2 & 3 \\
\hline
\end{tabular}

TABLE VI

PRICES IN THE SPOT MARKET

\begin{tabular}{c|c||c|c||c|c}
\hline Hour & $\begin{array}{l}\text { SpotPrice } \\
{[\mathrm{c} \$ / \mathrm{kWh}]}\end{array}$ & Hour & $\begin{array}{c}\text { SpotPrice } \\
{[\mathrm{c} \$ / \mathrm{kWh}]}\end{array}$ & Hour & $\begin{array}{c}\text { SpotPrice } \\
{[\mathrm{c} \$ / \mathrm{kWh}]}\end{array}$ \\
\hline 1 & 1.68 & 9 & 2.40 & 17 & 2.34 \\
\hline 2 & 1.57 & 10 & 2.54 & 18 & 2.48 \\
\hline 3 & 1.55 & 11 & 2.56 & 19 & 2.76 \\
\hline 4 & 1.53 & 12 & 2.54 & 20 & 2.76 \\
\hline 5 & 1.49 & 13 & 2.52 & 21 & 2.71 \\
\hline 6 & 1.51 & 14 & 2.43 & 22 & 2.56 \\
\hline 7 & 1.61 & 15 & 2.31 & 23 & 2.34 \\
\hline 8 & 1.88 & 16 & 2.33 & 24 & 2.27 \\
\hline
\end{tabular}

TABLE VII

LINE CHARACTERISTICS

\begin{tabular}{|c|c|c|c|c|c|c|c|c|c|c|c|}
\hline \multicolumn{2}{|c|}{ Line } & \multirow{2}{*}{$\begin{array}{l}\begin{array}{l}\text { Resist } \\
\text { [ohm] }\end{array} \\
0.194\end{array}$} & \multirow{2}{*}{$\frac{\begin{array}{l}l^{\max } \\
{[M W]}\end{array}}{8.28}$} & \multirow{2}{*}{$\begin{array}{c}\begin{array}{c}\lambda \\
\text { [out/yr] }\end{array} \\
0.277\end{array}$} & \multirow{2}{*}{$\begin{array}{c}\text { MTBF } \\
{[h]} \\
9.05\end{array}$} & \multicolumn{2}{|c|}{ Line } & \multirow{2}{*}{$\begin{array}{l}\text { Resist } \\
\text { [ohm] }\end{array}$} & \multirow{2}{*}{$\begin{array}{l}l_{\text {max }}^{\max } \\
{[M W]} \\
13.03 \\
\end{array}$} & \multirow{2}{*}{$\begin{array}{c}\lambda \\
\text { [out/yr] } \\
0.035\end{array}$} & \multirow{2}{*}{$\begin{array}{c}\text { MTBF } \\
{[h]} \\
5.05\end{array}$} \\
\hline 0 & 14 & & & & & 0 & 25 & & & & \\
\hline 14 & 16 & 0.068 & 8.28 & 0.097 & 9.05 & 12 & 22 & 0.415 & 1.10 & 0.400 & 8.05 \\
\hline 14 & 15 & 068 & .28 & 0.097 & 9.05 & 26 & 27 & $\overline{562}$ & 8.28 & 0.088 & 9.05 \\
\hline 16 & 17 & 0.046 & 8.28 & 0.066 & 9.05 & 27 & 28 & 0.099 & 8.28 & 0.141 & 9.05 \\
\hline 17 & 18 & 049 & 8.28 & 0.070 & 9.05 & 28 & 29 & 0.055 & 8.28 & 0.079 & 9.05 \\
\hline 18 & 19 & & 28 & 0.075 & 9.05 & 27 & 30 & & 8.28 & 0.066 & .05 \\
\hline 19 & 20 & 43 & 8.28 & 0.062 & 9.05 & 10 & 29 & 402 & 1.10 & 0.390 & 8.05 \\
\hline 20 & 21 & 0.055 & 8.28 & 0.079 & 9.05 & 31 & 32 & 0.062 & 8.28 & 0.088 & 9.05 \\
\hline 21 & 23 & & 70 & 0.086 & 12.98 & 40 & 10 & & 1.10 & 0.350 & 3.05 \\
\hline 23 & 24 & 60 & 5.70 & 0.036 & 12.98 & 33 & 34 & 0.062 & 8.28 & 0.088 & 9.05 \\
\hline 21 & 22 & 0.152 & 5.70 & 0.012 & 12.98 & 34 & 35 & 0.062 & 8.28 & 0.088 & 9.05 \\
\hline 0 & 1 & 24 & 13.03 & 0.041 & 5.05 & 35 & 39 & 62 & 8.28 & 0.374 & 9.05 \\
\hline 1 & 2 & 11 & 8.28 & 0.035 & 9.05 & 39 & 41 & 154 & 5.70 & 0.475 & 12.98 \\
\hline 2 & 3 & 0.011 & 8.28 & 0.035 & 9.05 & 41 & 42 & 62 & 5.70 & 0.190 & 12.98 \\
\hline 3 & 4 & 28 & 8.28 & 0.092 & 9.05 & 39 & 40 & 0.123 & 5.70 & 0.380 & 12.98 \\
\hline 4 & 5 & 12 & 8.28 & 0.040 & 9.05 & 35 & 36 & 992 & 5.70 & 0.285 & 12.98 \\
\hline 4 & 6 & 0.016 & 8.28 & 0.053 & 9.05 & 36 & 38 & 0.062 & 5.70 & 0.190 & 12.98 \\
\hline 6 & 7 & 0.012 & 8.28 & 0.040 & 9.05 & 36 & 37 & 0.062 & 5.70 & 0.190 & 12.98 \\
\hline 7 & 8 & 09 & 8.28 & 0.031 & 9.05 & 32 & 33 & 062 & 8.28 & 0.088 & 9.05 \\
\hline 8 & 13 & 0.028 & 8.28 & 0.092 & 9.05 & 24 & 42 & 0.513 & 1.10 & 0.450 & 8.05 \\
\hline 8 & 11 & 0.032 & 8.28 & 0.106 & 9.05 & 25 & 26 & 0.077 & 8.28 & 0.110 & 9.05 \\
\hline 11 & 12 & 0.039 & 8.28 & 0.128 & 9.05 & 7 & 15 & 0.405 & 1.10 & 0.413 & 8.05 \\
\hline 8 & 9 & 0.042 & 8.28 & 0.136 & 9.05 & 30 & 31 & 0.062 & 8.28 & 0.088 & 9.05 \\
\hline 9 & 10 & 0.023 & 8.28 & 0.075 & 9.05 & 34 & 38 & 0.406 & 1.10 & 0.380 & 8.05 \\
\hline
\end{tabular}

topology and the location of the disconnecting switches. Table $\mathrm{V}$ shows the maximum load of each feeder. Table VI presents the prices in the spot market. Table VII contains the line data characteristics.

\section{REFERENCES}

[1] F. C. Schweppe, M. C. Caramanis, R. D. Tabors, and R. E. Bohn, Spot Pricing of Electricity. Boston, MA: Kluwer, 1988, pp. 177-204.

[2] J. Román, T. Gómez, A. Muñoz, and J. Peco, "Regulation of distribution network business," IEEE Trans. Power Syst., vol. 14, no. 2, pp. 662-669, Apr. 1999

[3] J. T. Saraiva, J. L. Pinto Pereira da Silva, and M. T. Ponce de Leão, "Regulation, tariff schemes and quality of service-a discussion," in Proc. 2000 UIE_Int. Union of Electricity Applications, [Online] Available: http://power.inescn.pt/, Nov. 2000.

[4] H. Rudnick and J. A. Donoso, "Integration of price cap and yardstick competition schemes in electrical distribution regulation," IEEE Trans. Power Syst., vol. 15, no. 4, pp. 1428-1433, Nov. 2000.

[5] T. G. San Román, "Incentive Regulation for Distribution Companies Under Electricity Competition," Lawrence Berkeley National Lab., LBNL Internal Report, [Online] Available: http://www.iit.upco.es, Apr. 1999.

[6] J. W. Marangon Lima, C. C. Noronha, H. Arango, and P. E. Steele dos Santos, "Distribution pricing based on yardstick regulation," IEEE Trans. Power Syst., vol. 17, no. 1, pp. 198-204, Feb. 2002.

[7] L. Murphy, R. J. Kaye, and F. Wu, "Distributed spot pricing in radial distribution systems," IEEE Trans. Power Syst., vol. 9, no. 1, pp. 311-317, Feb. 1994.

[8] M. T. Ponce de Leão, "Marginal cost computation using simulated annealing," in Proc. IEEE Budapest Power Tech'99, Budapest, Hungary, Aug. 1999, paper BPT99-426-21, [Online] Available: http://power.inescn.pt/.

[9] M. T. Ponce de Leão and J. T. Saraiva, "Solving the revenue reconciliation problem of distribution network providers using long term marginal prices," IEEE Trans. Power Syst., vol. 18, no. 1, pp. 339-345, Feb. 2003.

[10] F. J. Rubio-Oderiz and J. I. Pérez-Arriaga, "Marginal pricing of transmission services," IEEE Trans. Power Syst., vol. 15, no. 1, pp. 448-454, Feb. 2000.

[11] D. Kirschen, "Demand-side view of electricity markets," IEEE Trans. Power Syst., vol. 18, no. 2, pp. 520-527, May 2003.

[12] - "Factoring the elasticity of demand in electricity prices," IEEE Trans. Power Syst., vol. 15, no. 2, pp. 612-617, May 2000.

[13] R. J. Kaye and H. R. Outhred, "A theory of electricity tariff design for optimal operation and investment," IEEE Trans. Power Syst., vol. 4, no. 2, pp. 606-613, May 1989.

[14] M. A. Farrag, M. Metwally, and M. S. El-Bages, "A new model for distribution system planning," Int. J. Elect. Power and Energy Syst., vol. 21, no. 7, pp. 523-531, Oct. 1999.

[15] B. H. Kim and M. L. Baughman, "The economic efficiency impacts of alternatives for revenue reconciliation," IEEE Trans. Power Syst., vol. 12, no. 3, pp. 1129-1134, Aug. 1997.

[16] J. M. Yusta, "Models for the Calculation of Optimal Prices of the Electricity in Electrical Distribution Systems in Deregulated Market," Ph.D. dissertation, Centro Politécnico Superior Universidad de Zaragoza, Zaragoza, Spain, 2000.

[17] J. A. Domínguez, J. M. Yusta, P. Pisa, and H. M. Khodr, "Optimal power flow algorithm based in Tabu search for meshed distribution networks," in Proc. 14th PSCC'2002, Sevilla, Spain, pp. 24-28.

[18] M. Rivier and I. J. Perez-Arriaga, "Computation and decomposition of spot prices for transmission pricing," in Proc. 11th PSCC'1993, Avignon, France.

[19] E. Khan, Electric Utility Planning and Regulation American Council for an Energy-Efficient Economy, American Council for an Energy Efficient Economy, Washington, DC, pp. 11-12, 1988.

[20] R. Billinton and R. N. Allan, Reliability Evaluation of Power Systems, 2nd ed. New York: Plenum, 1996, pp. 220-225.

[21] Y. R. Sood, N. P. Padhy, and H. O. Gupta, "Wheeling of power under deregulated environment of power system-a bibliographical survey," IEEE Trans. Power Syst., vol. 17, no. 3, pp. 870-878, Aug. 2002.

[22] M. Bazaraa, J. Jarvis, and H. Sherali, Linear Programming and Network Flows, 2nd ed. New York: Wiley, 1990, pp. 419-475.

[23] D. Shrimohammadi, X. V. Filho, B. Gorenstein, and M. V. P. Pereira "Some fundamental technical concepts about cost based transmission pricing," IEEE Trans. Power Syst., vol. 11, no. 2, pp. 1002-1006, May 1996.

[24] H. H. Happ, "Cost of wheeling methodologies," IEEE Trans. Power Syst., vol. 9, no. 1, pp. 147-156, Feb. 1994.

[25] B. L. P. P. Perera, E. D. Farmer, and B. J. Cory, "Revenue reconciled optimum pricing of transmission services," IEEE Trans. Power Syst. vol. 11, no. 3, pp. 1419-1424, Aug. 1996. 
[26] J. Y. Choi, S. H. Rim, and J. K. Park, "Optimal real time pricing of real and reactive powers," IEEE Trans. Power Syst., vol. 13, no. 4, pp. 1226-1231, Nov. 1998.

[27] I. J. Ramirez-Rosado and J. L. Bernal-Agustín, "Genetic algorithms applied to the design of large power distribution systems," IEEE Trans. Power Syst., vol. 13, no. 2, pp. 696-703, May 1998.

[28] A. S. Braga and J. T. Saraiva, "From short to long term marginal prices—advantages and drawbacks," in Proc. MedPower2002, Athens, Greece, [Online] Available: http://power.inescn.pt/.

[29] W. Nicholson, Microeconomic Theory, 7th ed. New York: Dryden Press, 1997, pp. 440-441.

[30] V. Miranda and J. T. Saraiva, "Fuzzy modeling of power system optimal load flow," IEEE Trans. Power Syst., vol. 7, no. 2, pp. 843-849, May 1992.

P. M. De Oliveira De Jesús (M’03) was born in Caracas, Venezuela, in 1971. He received the Elect. Eng. and M.Sc. degrees in 1995 and 2002 from the Universidad Simón Bolívar, Caracas, Venezuela. He is currenlty pursuing the Ph.D. degree at the Faculdade de Engenharia, Universidade do Porto (FEUP), Porto, Portugal.

He was previously an Assistant Professor of electrical engineering at the Universidad Simón Bolívar. He is currently a Researcher at the Instituto de Engenharia de Sistemas e Computadores (INESC Porto), Porto. His research interests include technical and economic issues of electric power systems.

M. T. Ponce de Leão (M'95) was born in Porto, Portugal, in 1957. She received the electrical and computer engineering degree and the Ph.D. degree from the Faculdade de Engenharia da Universidade do Porto (FEUP), Porto, Portugal, in 1980 and 1996, respectively.

Currently, she is a Professor in the electrical and computer department of FEUP. Since 1987, she has also been with the Instituto de Engenharia de Sistemas e Computadores (INESC Porto) as a Researcher. In recent years, she was involved in the development of DMS systems and the evaluation of impact of distributed generation in distribution planning.
J. M. Yusta (M'01) received the Ind. Eng. degree in 1994 and the Ph.D. degree in 2000 from the Engineer Higher Polytechnical Center, Universidad de Zaragoza, Zaragoza, Spain.

Currently, he is a Professor of Electrical Engineering at the Universidad de Zaragoza. His research interest includes technical and economic issues of distribution systems.

H. M. Khodr (M'99), received the B.Sc., M.Sc., and Ph.D. degrees in electrical engineering from the José Antonio Echeverría Higher Polytechnic Institute (ISPJAE) in 1993 and 1997, respectively.

He is presently a Professor of electrical engineering at the Universidad Simón Bolívar, Caracas, Venezuela. His research activities are concentrated in the planning, operation, and economics of electrical power systems.

A. J. Urdaneta (SM'90) received the Elect. Eng. (Hons.) degree from the Universidad Simón Bolívar, Caracas, Venezuela, in 1979, the M.Sc. degree in electrical engineering and applied physics in 1983, and the Ph.D. degree in systems engineering in 1986, both from Case Western Reserve University, Cleveland, $\mathrm{OH}$.

He is a Professor of electrical engineering, Department of Energy Conversion and Delivery, Universidad Simón Bolívar. He has been responsible for a number of projects and studies performed for local industries. He is the former Dean of Professional Studies and former Chairman of the IEEE Venezuelan Section. His research interests are in the area of power system analysis and optimization. 